\title{
Limulus assay for bacterial endotoxin in synovial fluid
}

\author{
THOMAS CESARIO, MARK JASON, BRIAN S. ANDREWS, \\ EDWARD SHANBRON, * DAVID JURANAS, * LEON KATZ, \\ AND GEORGE J. FRIOU
}

From the University of California Irvine, Department of Medicine, Divisions of Infectious Disease and Rheumatology and Clinical Immunology, and ${ }^{*}$ Mallinckrodt Inc, St Louis, MO, USA

SUMMARY The limulus assay for the detection of bacterial endotoxin has been applied to the study of synovial fluid. Three of 5 patients $(60 \%)$ with culture-positive gonococcal arthritis had positive SF limulus assay results; as did 2 of $11(18 \%)$ with presumptive evidence of gonococcal arthritis, 3 of $6(50 \%)$ with nongonococcal infectious arthritis, and none of 47 patients with noninfectious arthritis. Endotoxin levels ranged from 0.25 to $128.0 \mathrm{ng} / \mathrm{ml}$. As at present applied to synovial fluid the commercial limulus assay appears to be specific for the infectious process but apparently lacks sensitivity.

The detection of endotoxin by a sensitive, rapid test has long been a goal of the microbiologist attempting to supplant the time-consuming procedures involved in bacterial cultures. Such a test might also be used to detect fastidious organisms which fail to grow if not properly transported or cultured. Thus a simple assay method that could be applied to clinical specimens would have considerable advantages. The limulus assay provides a means of detecting relatively low endotoxin concentrations $(\mathrm{ng} / \mathrm{ml})$ in clinical specimens $^{1}$ and has been widely used. ${ }^{2}{ }^{3}$ In some body fluids, such as the cerebrospinal fluid, ${ }^{4}$ it appears to be of value. In other body fluids, particularly blood plasma, ${ }^{56}$ its value is more problematical, at least partly because of the presence of substances ${ }^{7}$ which appear to inhibit the gelation reaction necessary for interpretation of the test.

It would seem to be particularly useful to apply a technique for endotoxin analysis to synovial fluid (SF), since Neisseria gonorrheae is a major cause of septic arthritis, produces endotoxin, and may escape detection unless transported and cultured under optimal conditions. Furthermore, should this assay, when applied to SF, prove sensitive and specific, it might help resolve the question of whether culturenegative arthritis occurring during disseminated gonococcal disease is due to the presence of undetected organisms in the joint or to some entirely different immunopathological process (e.g., immune

Accepted for publication 6 September 1982.

Correspondence to Thomas Cesario, MD, Department of Medicine, Division of Infectious Disease, Route 81, University of California Irvine Medical Center, Orange, CA 92668, USA. complex deposition) occurring in the absence of bacteria. Earlier reports have described the use of the limulus assay for $\mathrm{SF}^{8}{ }^{8}$ These authors, using reagents prepared in their own laboratory, found the assay on SF to be sensitive but not specific. We have performed the limulus assay on 69 specimens of synovial fluid obtained from patients with a variety of rheumatological diseases. The assay appeared to be relatively specific for septic processes but lacked sensitivity.

\section{Materials and methods}

Synovial fluid was obtained from patients undergoing diagnostic arthrocentesis for clinical indications as determined by the attending physician. Samples were collected in sterile disposable tubes and delivered to the laboratory, where they were transfered to sterile glass vials and frozen at $-80^{\circ} \mathrm{C}$ until the endotoxin assay was performed.

Limulus amoebocyte lysate. The limulus assay was performed with a commercially available lysate (Mallinckrodt, Inc, St Louis, MO), which was rehydrated with sterile water for injection USP (Abbott) just prior to assay. All laboratory ware used was depyrogenated prior to use by heating at $250^{\circ} \mathrm{C}$ for one hour. The test was performed by adding $100 \mu \mathrm{l}$ of joint fluid or diluted joint fluid to a depyrogenated $10 \times 75 \mathrm{~mm}$ glass test tube. The lysate reagent in 100 $\mu l$ quantities was then added to each sample tube and incubated for one hour at $37^{\circ} \mathrm{C}$. The lysate tests were read by gently inverting each tube through $180^{\circ}$. A 
gel that maintained its integrity after its inversion was recorded as a positive test.

Total endotoxin concentrations were determined by serially diluting the joint fluids in 2-fold increments with pyrogen-free water. Each dilution was tested with the lysate reagent until a negative lysate test was obtained. The highest positive dilution was multiplied by the lysate sensitivity (previously determined to be $0.0125 \mathrm{ng} / \mathrm{ml}$ with Escherichia coli 055:B5 endotoxin, Mallinckrodt, Inc) to yield the total endotoxin concentration.

For the purpose of this study infectious arthritis (8 patients) was defined as arthritis in which the SF culture was positive for bacteria. Presumed infectious arthritis (14 patients) was diagnosed when the clinician(s) caring for the patient viewed the arthritis as an infectious process but where the SF bacterial culture results were negative (6 patients) or the results unavailable (5 patients). Noninfectious arthritis (47 patients) was that in which the rheumatic condition appeared to be entirely unrelated to bacterial infection, with a negative SF culture.

\section{Results}

Synovial fluid was obtained from 69 patients. Table 1 shows the underlying joint diseases of these patients. Twenty-two patients had infectious or presumed infectious arthritis and 47 noninfectious conditions. The limulus assay was negative when performed on SF from all patients with noninfectious arthritis. Of the 8 patients with definite infectious arthritis 5 had positive limulus assays (Table 2). Included in these 8 patients were 5 with gonococcal arthritis, one with

Table 1 Aetiological distribution of synovial fluid samples

\begin{tabular}{lc}
\hline Definite infectious & \\
N. gonorrheae & 5 \\
Ps, aeruginosa & 1 \\
Staph. aureus & 2 \\
Total & 8 \\
Presumed infectious & $11^{*}$ \\
N. gonorrheae & $3 \dagger$ \\
Nongonococcal & 14 \\
Total & 16 \\
Noninfectious & 14 \\
Rheumatoid arthritis & 8 \\
Degenerative joint disease & 9 \\
Gout or pseudogout & 47 \\
Miscellaneous & \\
Total & 69 \\
Total &
\end{tabular}

"In 6 patients the SF culture was negative for bacteria and in 5 patients the results of the cultures were unavailable.

†Includes 2 patients with negative SF cultures and one with unknown culture results.
Table 2 Results of limulus assay on synovial fluids from patients with infectious and noninfectious arthritis

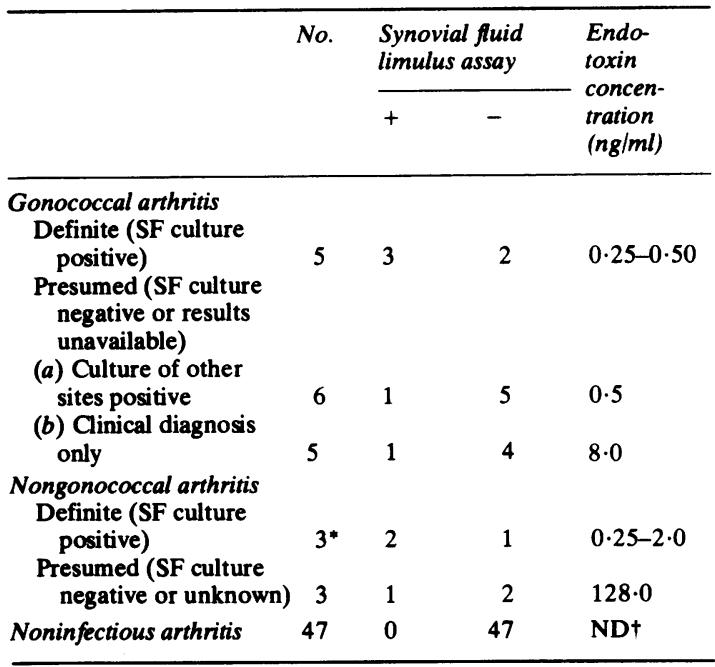

*Two patients had positive synovial cultures for Staph. aureus and one for Ps. aeruginosa.

†ND=not detected.

arthritis secondary to Pseudomonas aeruginosa, and 2 with arthritis caused by Staphylococcus aureus. Three patients with gonococcal arthritis, one with $P$ s. aeruginosa arthritis, and one with Staph. aureus arthritis had positive limulus assays.

Among the 14 patients with presumed infectious arthritis only 3 had positive limulus assays. These included two of 11 with suspected gonococcal disease and one of 3 with suspected nongonococcal infectious arthritis. The levels of endotoxin encountered in SF are detailed in Table 2.

\section{Discussion}

These studies show that similar problems to those encountered in the adaptation of the limulus assay to specimens of blood or plasma may also be encountered in the testing of SF. Thus, Stumacher et al. ${ }^{5}$ found positive limulus assays in the blood of 28 of 65 patients with Gram-negative bacteraemia but also in the blood of 8 of 22 patients with Gram-positive bacteraemia. In this same study nonbacteraemic infections due to Gram-negative rods were also associated with endotoxaemia in 11 of 32 cases. Elin et al., ${ }^{6}$ using a panel of 7 different lysate preparations, applied the limulus assay to plasma. They found 12 of 29 specimens from bacteraemic patients had positive gelation reactions with at least one of the lysate samples used. However, 4 of the positive samples were 
from patients with Gram-positive bacteraemia. In contrast, Levin et al. ${ }^{7}$ found that 12 of 17 patients with Gram-negative sepsis had positive limulus assays, but all controls, including some patients with Gram-positive infections, had negative test results. These data indicate that not all lysate preparations are effective in the assay and that occasionally organisms considered to be endotoxin-negative may result in false positive tests. In contrast to the results obtained with blood Nachum et al. ${ }^{4}$ demonstrated that the test is both sensitive and specific in cerebrospinal fluid.

In the current study we have applied the limulus assay to SF samples. All of the $47 \mathrm{SF}$ samples that we tested from patients with noninfectious arthritis had negative limulus assays. Thus the assay demonstrated specificity for infectious arthritis. However, among the 22 patients with infectious or presumed infectious arthritis only 8 specimens were found to give positive results in the limulus assays. Particularly disconcerting was a positive result in one of 2 patients with Staph. aureus infectious arthritis. Since Staph. aureus is a Gram-positive organism and should not contain endotoxin, ${ }^{10}$ a positive test in this setting must be considered to be a false positive reading. Possible alternative explanations include specimen contamination or presence of 2 organisms within the joint. Furthermore, 2 patients with culture-positive gonococcal arthritis had negative limulus assays. Thus, as with serum samples, we have found both false negative and false positive reactions. Conversely, however, it was important to note that false positive assays were not encountered in the group with noninfectious arthritis. The low sensitivity of the tests may relate to the dilution of the SF prior to assay.

Our results reported here differ from those of Elin et al. ${ }^{8}$ who used their own lysate preparation. They found endotoxin could be detected in all cases of septic arthritis, including those with negative joint fluid cultures. They also found endotoxin could be found by the limulus assay in the SF of a substantial percentage of patients with rheumatoid arthritis, gout, Reiter's syndrome, and miscellaneous other conditions. They concluded that the limulus assay was not specific for septic processes. Tuazon et al. ${ }^{9}$ used the limulus assay to detect endotoxin in SF. They found 6 patients with culture-proved septic arthritis who had positive endotoxin assays, though 2 were patients with Gram-positive infections. The differences seen between the results of ourselves and Elin et al. may result from dissimilarities in the preparation of the lysate. We used a commercially available preparation. Using this lysate we found no false positives in patients with nonseptic conditions but failed to detect endotoxin in several culture-positive
SF samples. It has previously been shown that the lysate used does effect the results of the assay. ${ }^{6}{ }^{11}$

As there appear to be some limitations with the limulus assay when applied to samples of SF, we are unable to draw any definite conclusions regarding patients with presumed gonococcal disease with negative limulus assays. However, when the assay was applied to SF with culture-negative gonococcal arthritis, which was definitely diagnosed in 6 patients in this study from the presence of positive gonococcal cultures at other sites, a negative limulus assay was present in $5(83 \%)$. This would be compatible with our previous suggestions ${ }^{12}$ that culture-negative gonococcal arthritis may result from either local formation of immune complexes within the SF or deposition within the synovial membrane of circulating immune complexes. Paralleling the data on serum analysis certain substance(s) appear to inhibit the gelation reaction, with resulting false negative results. This may afford an alternative explanation for some false negative results with SF, but it remains to be established.

Future research is being focused on the refinement of the limulus assay with respect to sensitivity and the elimination of potential false positive and false negative results, which are necessary before routine clinical application of this assay for synovial fluid analysis can be undertaken.

We are grateful for the invaluable secretarial assistance of Cynthia Schaeffer, the word processing skills of Penny Gebert, and the laboratory assistance of Gloria Carandang.

This work was supported by the Kroc Foundation and the Arthritis Foundation.

\section{References}

1 Levin J, Bang F B. The role of endotoxin in the extracellular coagulation of limulus blood. Johns Hopkins Med J 1964; 115: 265-74.

2 Caridis D, Reinhold R, Woodruff P, Fine J. Endotoxaemia in man. Lancet 1972; i: 1381-5.

3 Levin J, Poore T, Young N, et al. Gram-negative sepsis: detection of endotoxemia with the limulus test. Ann Intern Med 1972; 76: 1-7.

4 Nachum R, Lipsey A, Siegel S. Rapid detection of Gramnegative bacterial meningitis by the limulus lysate test. $N$ Engl J Med 1973; 289: 931-4.

5 Stumacher R, Kovnat M, McCabe W M. Limitations of the usefulness of the limulus assay for endotoxemia. $N$ Engl $J$ Med 1973; 288: 1261-4.

6 Elin R, Robinson R, Levine A, Wolff S. Lack of clinical usefulness of the limulus test in the diagnosis of endotoxemia. $N$ Engl $J$ Med 1975; 293: 521-4.

7 Levin J, Tomasulo P, Oser R. Detection of endotoxin in human blood and the demonstration of an inhibitor. J Lab Clin Med 1970; 75: 903-11.

8 Elin R J, Knowles R, Barth W, Wolff S. Lack of specificity of the limulus lysate test in the diagnosis of pyogenic arthritis $J$ Infect Dis 1978; 137: 507-13. 
9 Tuazon C, Perez A, Elm R, Sheagren J. Detection of endotoxin in cerebrospinal fluids by limulus assay. Arch Intern Med 1977; 137: 55-6.

10 Willet H. Staphylococcus. In: Joklik W, Willet H, Amos D B, eds. Zinsser's Microbiology. 17th ed. New York: AppletonCentury Crofts, 1980: 532-52.

11 Prior R, Spagne V. Response of several limulus amoebocyte lysates to native endotoxin present in gonococcal and nongonococcal urethral exudates. J Clin Microbiol 1981; 13: 167-70.

12 Martin D, Andrews B, Friou G. Identification of immune complexes in synovial fluids and sera of patients with disseminated gonococcal infections (DGI) using the Raji cell assay. Arthritis Rheum 1981; 24: 574 